\title{
Role of Mini-implants in Orthodontics
}

\author{
${ }^{1}$ US Krishna Nayak, ${ }^{2}$ Nikhil Malviya \\ ${ }^{1}$ Dean, Senior Professor and Head, Department of Orthodontics and Dentofacial Orthopedics, AB Shetty Memorial Institute of Dental Sciences \\ Mangalore, Karnataka, India \\ ${ }^{2}$ Postgraduate Student, Department of Orthodontics and Dentofacial Orthopedics, AB Shetty Memorial Institute of Dental Sciences \\ Mangalore, Karnataka, India
}

Correspondence: US Krishna Nayak, Dean, Senior Professor and Head, Department of Orthodontics and Dentofacial Orthopedics AB Shetty Memorial Institute of Dental Sciences, Derlakatte, Mangalore, Karnataka, India, e-mail: dr_krishnanayak@yahoo.com

\section{ABSTRACT}

Anchorage has been a worrisome factor since the origin of orthodontics. Many modalities have been suggested in the scientific literature like extraoral anchorage with head gears, Intraoral anchorage with Nance palatal arches and reinforcement of anchorage units with addition of second molars, etc. Yet, the specialty of orthodontics did not find a solution for this problem until the introduction of miniimplants. Orthodontic implants are different from the ones used for prosthetics as there is no osseointegration. Mini-implants provide absolute anchorage and have revolutionized the field of orthodontics. This article reviews the indication, contraindications and their clinical applications in orthodontics.

Keywords: Mini-implants, Anchorage.

\section{INTRODUCTION}

Dental implants, which have been well described in the prosthodontic literature, are also used in orthodontic practice. More recently, smaller implants were introduced as temporary skeletal anchorage devices (TSADs) (Fig. 1). This article reviews the use of implants in orthodontics.

There are substantial differences between conventional implants and TSADs:

a. Conventional prosthodontic implants, generally loaded after osseointegration, are intended to be permanent whereas implants for orthodontic anchorage are usually loaded long before osseointegration is achieved, are intended to be removed relatively soon

b. Conventional implants are subject to high intermittent forces of mastication, but forces acting on orthodontic anchors are light and continuous

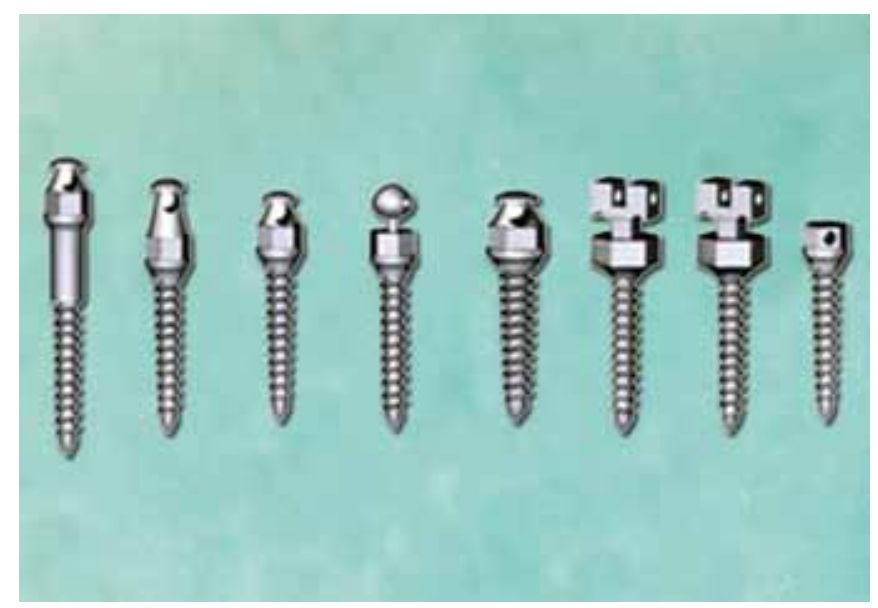

Fig. 1: Temporary anchorage devices c. The direction of loading and the size of the implants also vary between the two systems.

\section{Implant Terminology}

Implant: As defined by Boucher, implants are alloplastic devices which are surgically inserted into or onto jaw bone.

Osseointegration: An intimate structural contact at the implant surface and adjacent vital bone, devoid of any intervening fibrous tissue-Branemark (1983).

From the view point of stability, an osseous interface is more desirable than a fibrous interface.

\section{CLASSIFICATION ${ }^{1,2}$}

Implants can be broadly classified under the following:

\section{Based on the Location}

Subperiosteal: In this design, the implant body lies over the bony ridge. This type has had the longest history of clinical trials but a decreased long-term success rate; probably due to the fact that the chances of getting it dislodged are high. Also, the complexity of their designs requires a precise casting procedure. The subperiosteal design currently in use for orthodontic purposes is the 'Onplant'.

Transosseous: In this particular variety, the implant body penetrates the mandible completely. These have enjoyed good success rate in the past. However, they are not widely used because of the possible damage to the intrabony soft tissue structures, like the nerves and vessels. Even in the field of orthodontics, transosseous implants have not been used. 
Endosseous: These are partially submerged and anchored within bone. These are the most popular and the widely used ones. Various designs and compositions are available for usage in specific conditions. The endosseous implants are also the most commonly employed types for orthodontic purposes.

\section{Based on the Configuration Design}

Root form implants: These are the screw type endosseous implants and the name has been derived due to their cylindrical structure.

Screw designs: These include:

i. Dentos absoanchor implant system

ii. Aarhus implant

iii. Spider screw, the OMAS system, the Leone miniimplant.

\section{Blade/Plate Implants}

Plate designs: These include:

i. Skeletal anchorage system (SAS)

ii. Graz implant-supported system

iii. Zygoma anchorage system.

\section{According to the Composition}

- Stainless steel

- Cobalt-chromium-molybdenum (Co-Cr-Mo)

- Titanium:

- Alpha

- Beta

- Alpha-Beta phase (most commonly used)

- Ti-6Al-4V

- Ceramic implants

- Miscellaneous, such as vitreous carbon and composites.

\section{According to the Surface Structure}

\section{Threaded or Nonthreaded}

The root form implants are generally threaded as this provides for a greater surface area and stability of the implant.

\section{Porous or Nonporous}

The screw type implants are usually nonporous, whereas the plate or blade implants (nonthreaded) have vents in the implant body to aid in growth of bone, and thus, a better interlocking between the metal structure and the surrounding bone.

\section{Contraindication for Implant Therapy ${ }^{2}$}

\section{Absolute Contraindications}

- Severe systemic disorder, e.g. osteoporosis

- Psychiatric diseases, e.g. psychosis dysmorphia

- Alcoholics and drug abusers.

\section{Relative Contraindications}

- Insufficient volume of bone

- Poor bone quality

- Patients undergoing radiation therapy

- Insulin dependent diabetes

- Heavy smokers.

\section{SELECTION OF MICROIMPLANT SITES AND SIZES ${ }^{1}$}

Microimplants with diameters ranging from 1.2 to $1.6 \mathrm{~mm}$ are small enough to be placed anywhere in the mouth.

Microimplant lengths of more than $6 \mathrm{~mm}$ in the maxilla, and $5 \mathrm{~mm}$ in the mandible are recommended.

\section{Maxilla (Figs 2 to 4 ) \\ Infrazygomatic Crest Area}

Recommended microimplant size: Diameters of 1.3 and $1.4 \mathrm{~mm}$ and a length of 5 to $6 \mathrm{~mm}$.

\section{Maxillary Tuberosity Area}

Recommended microimplant size: Diameters of 1.3 and $1.5 \mathrm{~mm}$ and a length of 7 to $8 \mathrm{~mm}$.

\section{Between the Maxillary First Molar and Second Premolar Buccally}

Recommended microimplant size: Diameters of 1.2 and $1.3 \mathrm{~mm}$ and a length of 7 to $8 \mathrm{~mm}$.

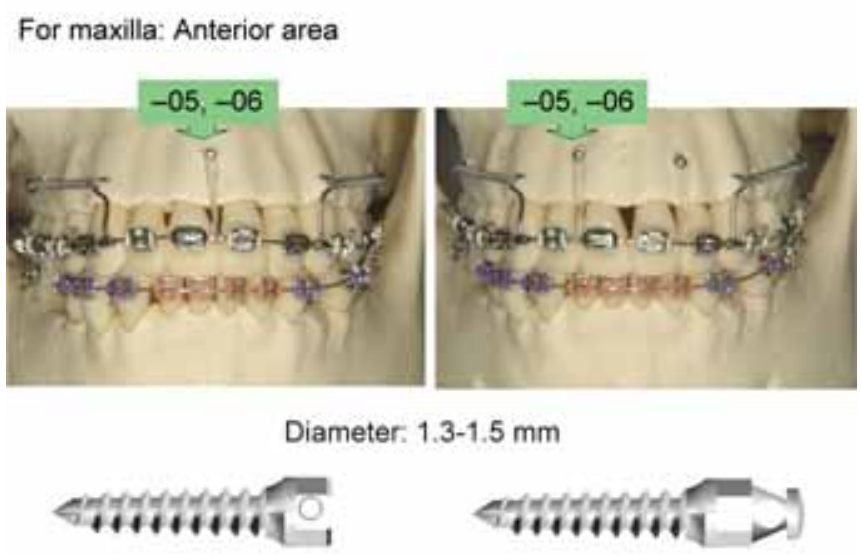

Fig. 2: Optimum TAD length for maxillary anterior area 


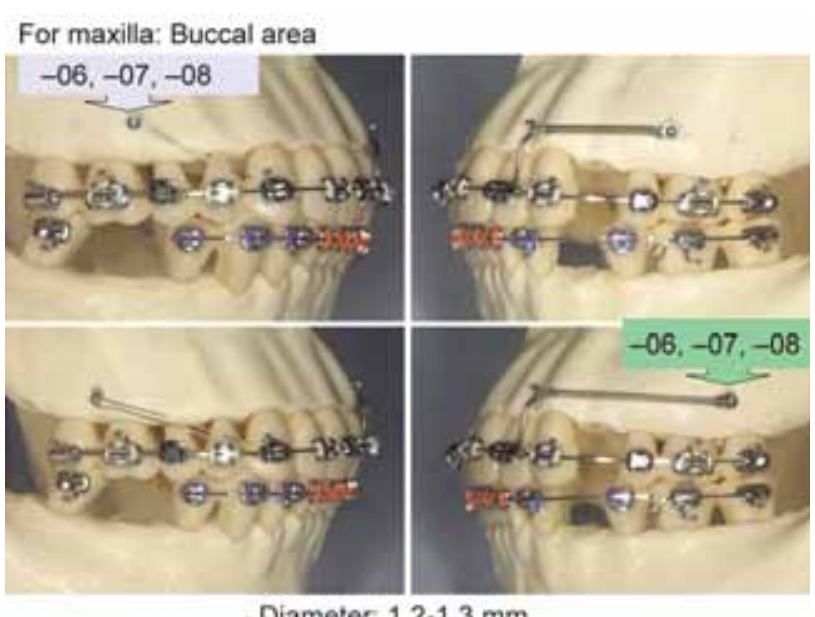

Diameter: $1.2-1.3 \mathrm{~mm}$

Fig. 3: Optimum TAD length for maxillary buccal area

For maxilla: Palatal area

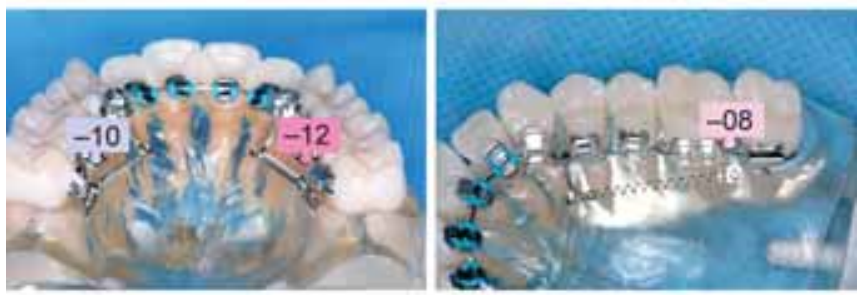

Diameter. 1.4-1.6 mm

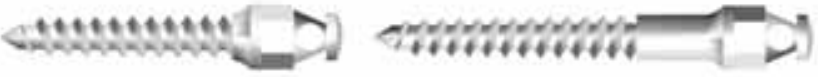

Fig. 4: Optimum TAD length for maxillary palatal area

\section{Between the Incisors Facially}

Recommended microimplant size: Diameters of 1.3 and $1.6 \mathrm{~mm}$ and a length of 6 to $7 \mathrm{~mm}$.

\section{Between the Maxillary First Molar and Second Premolar Palatally}

Recommended microimplant size: Diameters of 1.3 and $1.6 \mathrm{~mm}$ and a length of 10 to $12 \mathrm{~mm}$.

\section{Mid-Palatal Area}

Recommended microimplant size: Diameters of 1.5 and $1.8 \mathrm{~mm}$ and a length of 5 to $6 \mathrm{~mm}$.

\section{Mandible (Figs 5 to 7 )}

\section{Retromolar Area}

Recommended microimplant size: Diameters of 1.4 and $1.6 \mathrm{~mm}$ and a length of 5 to $10 \mathrm{~mm}$.

\section{Between the Mandibular First Molar and Second Premolar Bucally}

Recommended microimplant size: Diameters of 1.3 and $1.6 \mathrm{~mm}$ and a length of 5 to $7 \mathrm{~mm}$.

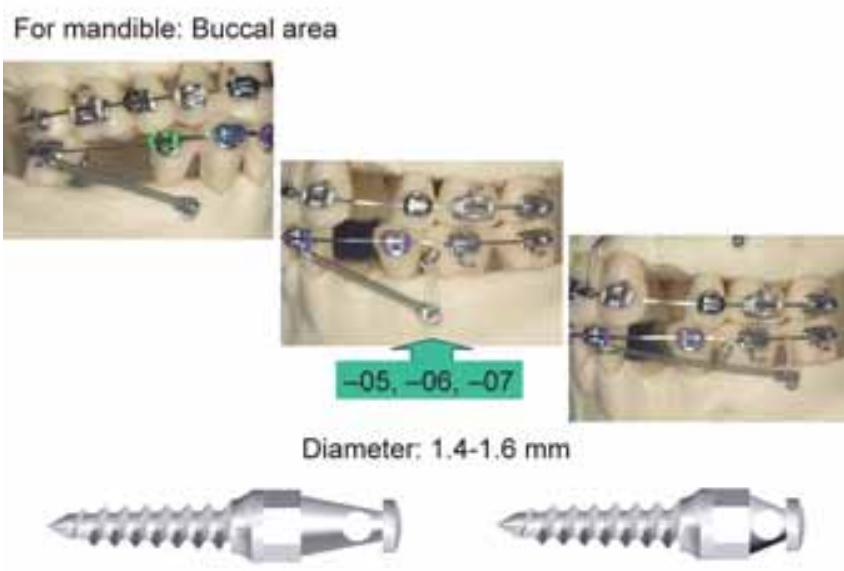

Fig. 5: Optimum TAD length for mandibular buccal area

For mandible: Anterior area

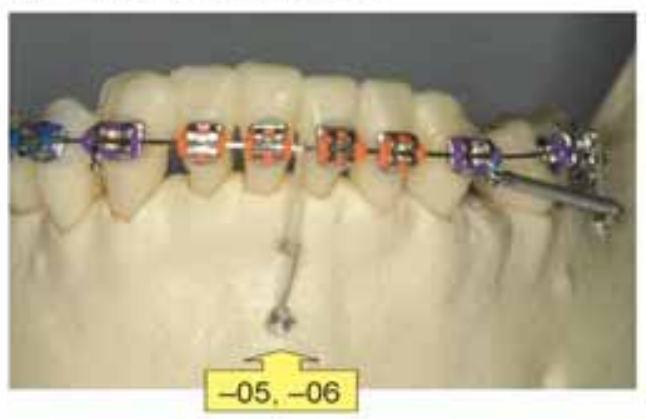

Diameter: $1.2-1.3 \mathrm{~mm}$

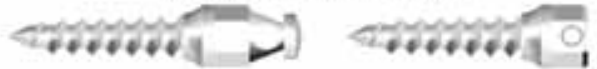

Fig 6: Optimum TAD length for mandibular anterior area

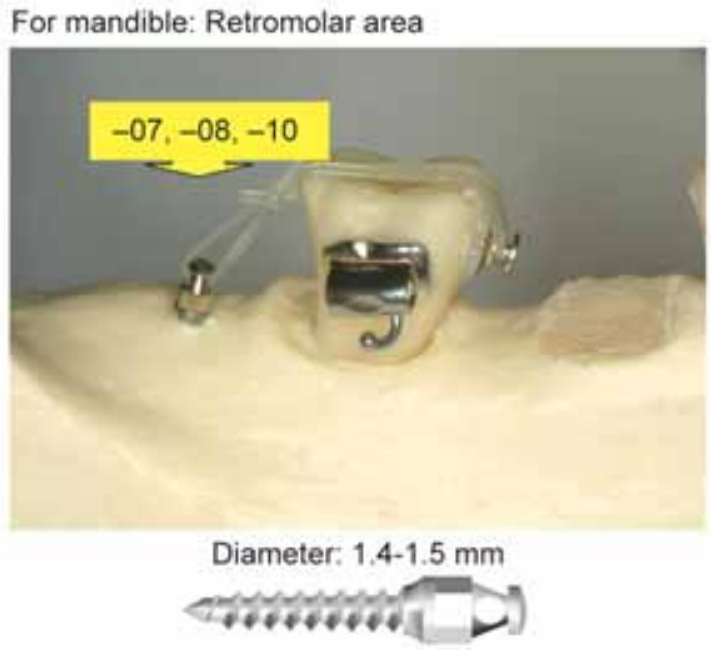

Fig. 7: Optimum TAD length for mandibular retromolar area

\section{Mandibular Symphysis Facially}

Recommended microimplant size: Diameters of 1.3 and 1.4 $\mathrm{mm}$ and a length of 5 to $6 \mathrm{~mm}$. 


\section{SURGICAL PROCEDURES FOR MICROIMPLANT PLACEMENT (FIGS 8A TO D)}

\section{Driving Method}

Self-tapping (predrilling) method: A tunnel is drilled into the bone first with a pilot drill, and then the implant is driven into the tunnel. This method is used when inserting microimplants that are small in diameter and made of low grade pure titanium or when the cortical bone is dense, e.g. mandible.

Self-drilling (drilling free) method: The implant itself acts as a drill as it is being inserted into the bone. It can be used when larger diameter titanium microimplants or microimplants made of titanium alloy are inserted.

\section{Steps in Implant Placement ${ }^{2}$}

IOPA with a surgical guide is placed to determine suitability of the site.

Anesthesia for implant placement: Local infiltration is usually adequate. Patient experiences pain only if drill approximates the roots.

Surgical incision: If the surrounding tissue is soft and mobile, a $5 \mathrm{~mm}$ surgical incision is done to prevent rolling up of tissue. Drill can be used to penetrate mucosa attached to gingiva and bone directly in firm tissue.
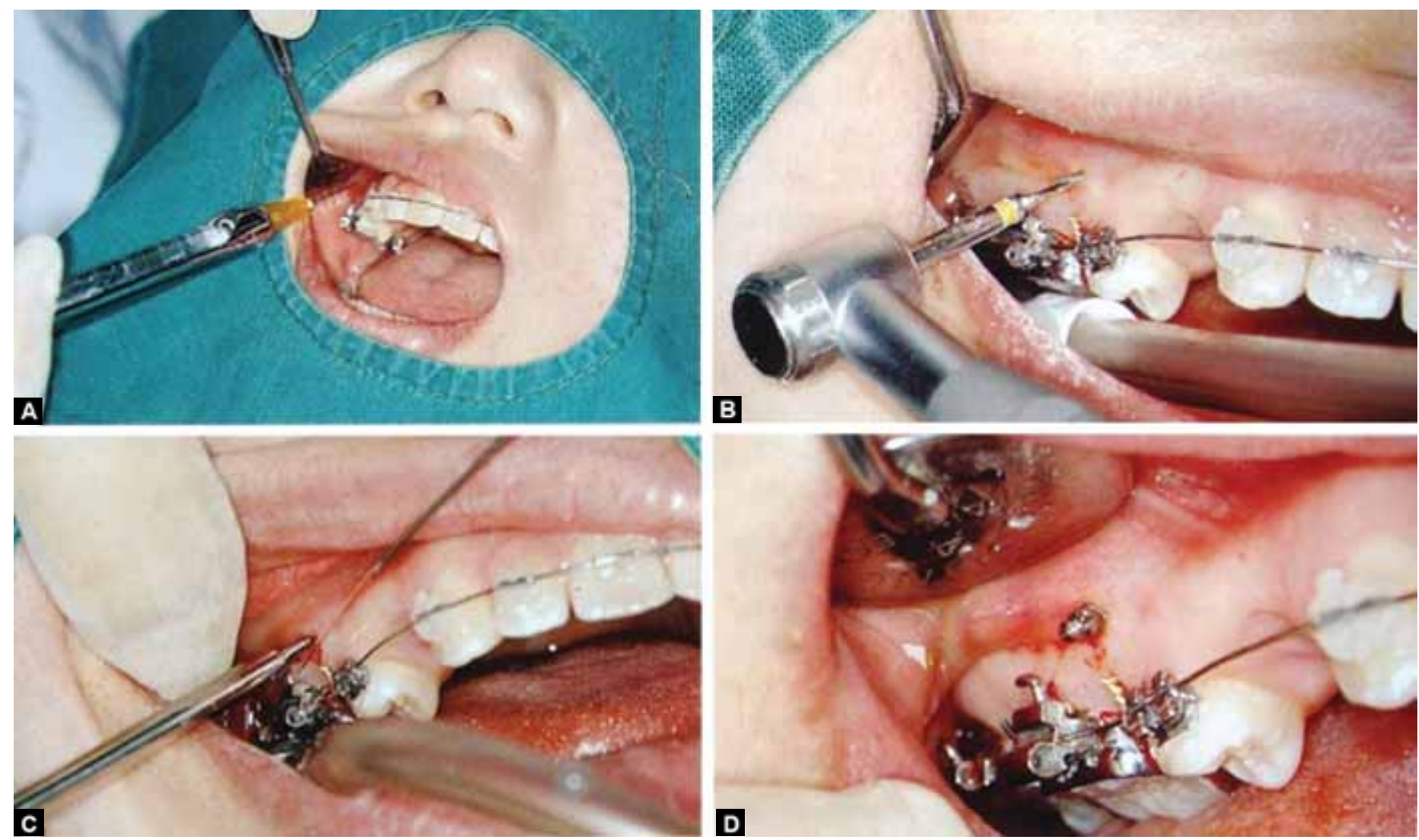

B

\section{CLINICAL APPLICATIONS OF MICROIMPLANTS IN ORTHODONTICS}

\section{Implants for Space Closure Cl,4 $^{3,4}$}

For posterior space closure the anterior-posterior location of the miniscrew is between roots of the first molars and the second bicuspids. Vertically, the miniscrew should be located at or above the mucogingival line depending on the desired line of action.

- For intrusion and distalization—above the mucogingival line

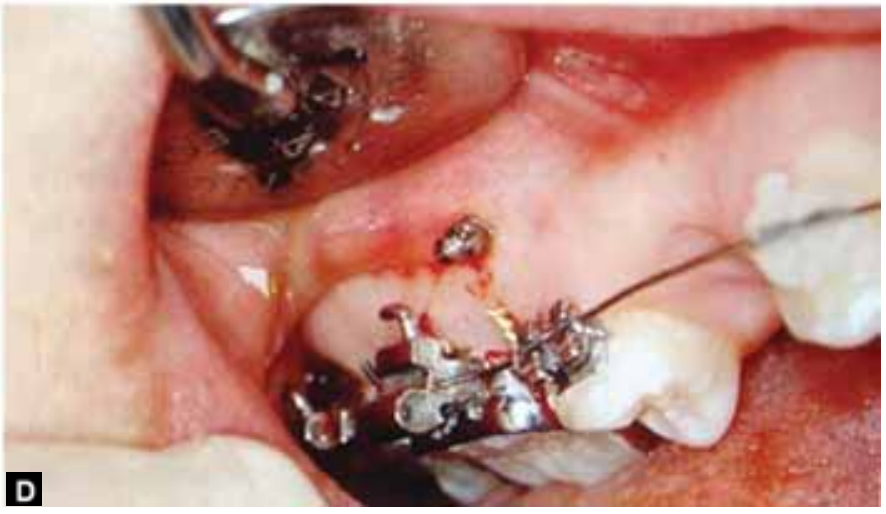

D

Figs 8A to D: Implant placement procedure (A) anesthesia (B) pilot drill, (C) implant placement, (D) placed implant 
- For distal movement - at level of the mucogingival line. Higher the screw in the maxilla the more perpendicular it is, in order to avoid damage to the maxillary sinus. Ideally it is 30 to 40 degree.

In case the alveolar process is too prominent an auxillary attachment (monkey hook) is used as it avoids discomfort and possible ulceration of the gums.

In the mandibular arch care should be taken to avoid the mental foramen.

Palatal microimplants can also be used in conjunction with lingual orthodontics for retraction of teeth.

\section{Intermaxillary Anchorage}

Class II correction is done by elastics or anterior repositioning appliances (i.e. Jasper Jumper, Bite Fixer, etc.). There are numerous unwanted side effects of these kinds of mechanics, such as excessive anterior movement (proclination and protrusion) of the lower incisors and opening of the bite, to name a few (Fig. 9). To address the above problems, one alternative may be to place miniscrews between the roots of the first and second lower molars or between the root of the second bicuspids and lower first
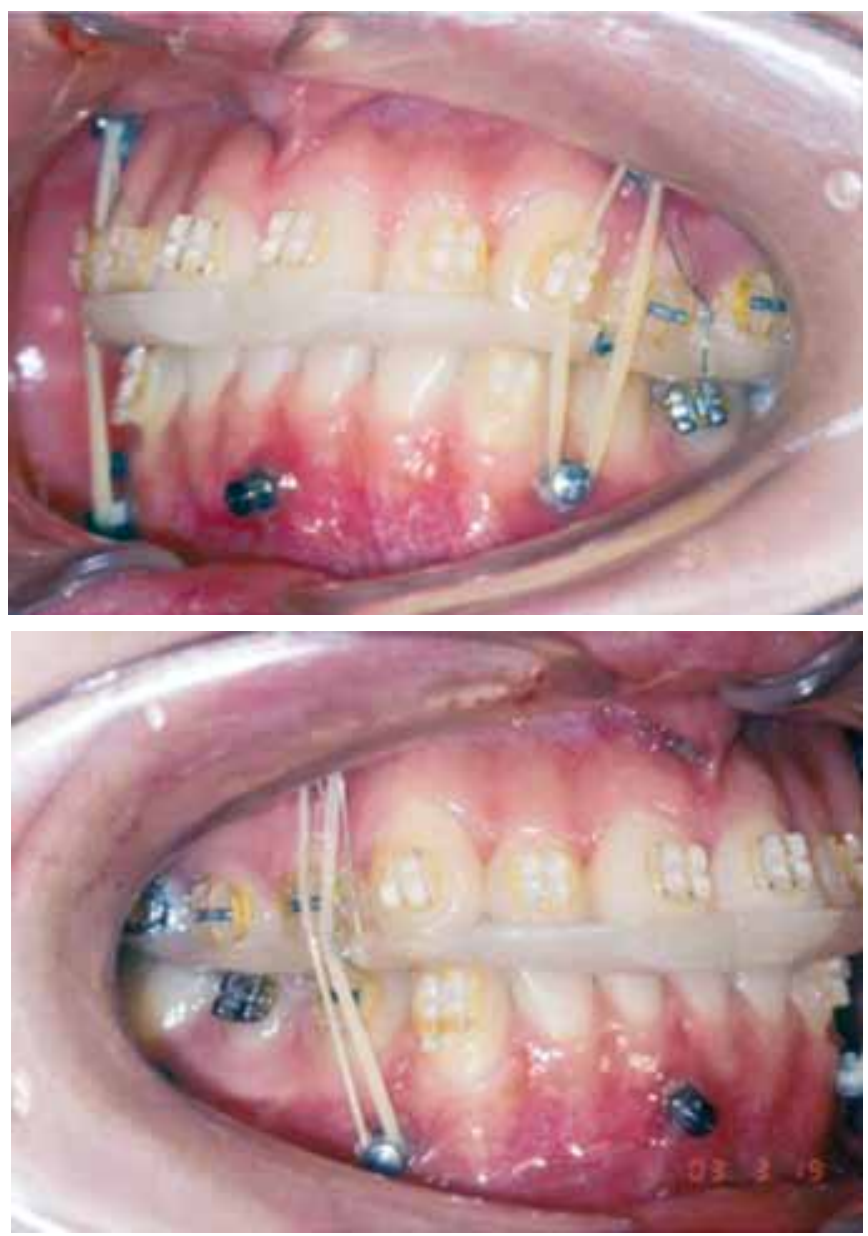

Fig. 9: Implants used for intermaxillary fixation following surgery molars, in this way the upper arch can be retracted without any unwanted dental effects on the lower teeth. The placement of the miniscrews mesial to the lower molar may also prevent the mesial movement of the entire lower arch because the miniscrews, when in contact with the lower molar, may not allow it to move anteriorly.

\section{Intrusion of Anterior Teeth ${ }^{5}$}

Creekmore in 1983 published a case report on usage of a vitallium implant for anchorage, while intruding the upper anterior teeth (Figs 10A and B). The vitallium screw was inserted just below the anterior nasal spine. After an unloading period of 10 days, an elastic thread was tied from head of the screw to the archwire. Within one year, $6 \mathrm{~mm}$ intrusion was demonstrated along with 25 lingual torque.

To intrude the upper incisors, the screw is placed between the upper lateral incisors and the canines. The placement of the miniscrews should be done after leveling and alignment, in order to maximize the interadicular space at the placement site.

In order to avoid tipping the upper incisors buccally during the intrusion, the end of the archwire should be
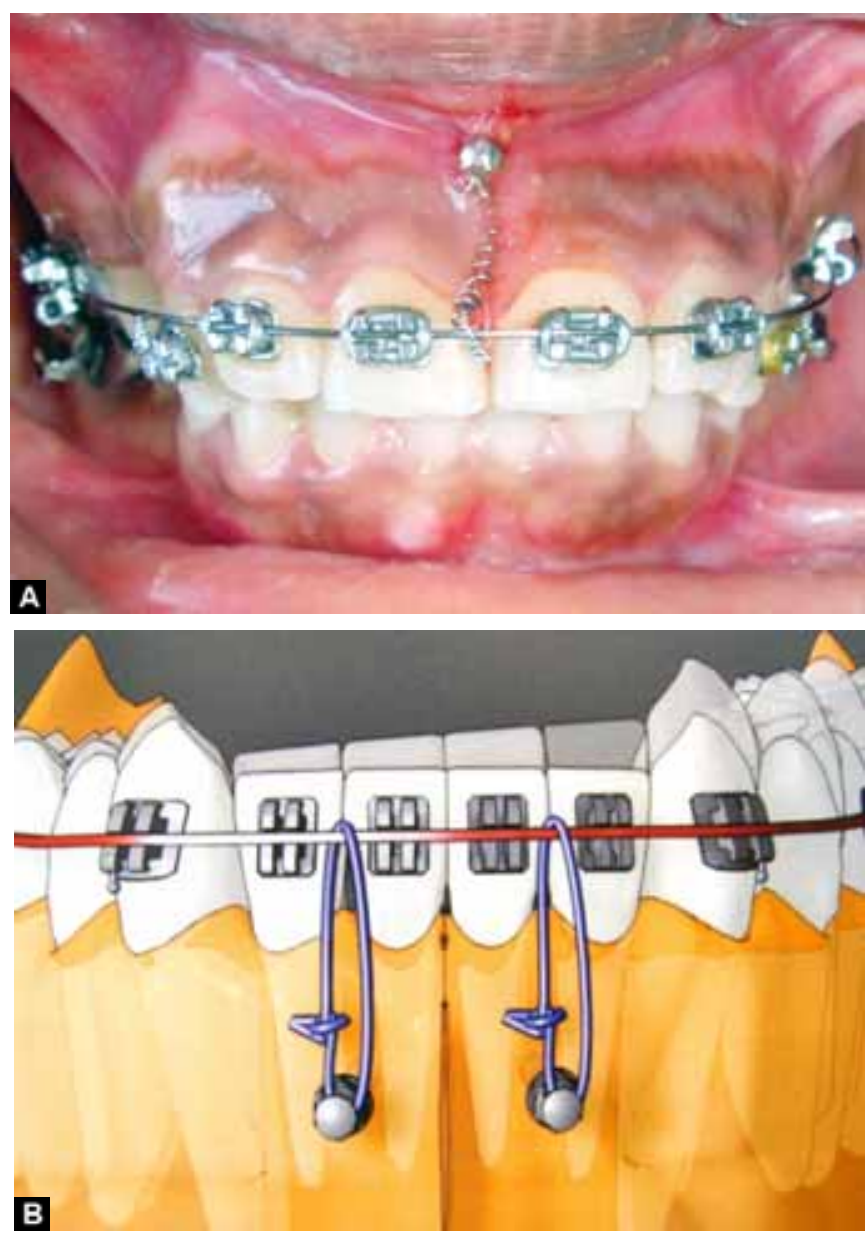

Figs $10 A$ and $B$ : Implants used for intrusion in $(A)$ maxillary anteriors, (B) mandibular anteriors 
cinched back. Correction of the cant of the plane of occlusion and of the dental midline, the miniscrew is used as anchorage to intrude the extruded canines and the laterals on the side of the cant, and to center the dental midline. During the intrusive movements, it is very important to center the miniscrews in between the roots of the teeth that need to be intruded in order to avoid the interferences between the teeth and the screw.

\section{Molar Intrusion 6}

It is very hard to place the microscrews precisely between the roots of first and second molars without interfering with the roots of the teeth either during implantation or during the intrusive movements. Moreover, sometimes the intrusion force need to be relatively high and more than one screw might be necessary in places where there is insufficient space available for the screw placement. For the above reasons, it is suggested to limit the use of the miniscrews to cases of simple molar intrusion of one or two teeth.

\section{Molar Distalization and Molar Protraction? (Figs 11 to 13)}

To correct class II or class III molar relationships, sometimes it is necessary to distalize molars. Microimplants can be placed between the roots of second premolar and the first molar, and nickel-titanium coil springs can be used. After molar distalization, the anterior teeth will need to be retracted. The first microimplant can be removed if it interferes with this retraction, and a second microimplant is placed just distal to the first one or between the first molar and second molar roots. For molar distalization, orthodontic forces can be applied from a microimplant to the center portion of the transpalatal arch.

Molar protraction is one of the most difficult tooth movements to accomplish, especially in patients with a low mandibular plane angle and deep bite. If microimplants are incorporated in the treatment protocol, molar teeth can be moved more effectively and without disturbing the anterior teeth. Microimplants for molar protraction are placed between the roots of canine and first premolar or between first premolar and second premolar roots.

\section{Correction of Molar Crossbites}

Correcting scissors bite with conventional orthodontic mechanics requires the use of through the bite elastics, however, if these elastics are used, undesirable extrusion of the posterior teeth may occur. But if microimplants are used, same type of uprighting and intrusion is observed during buccal crossbite correction.

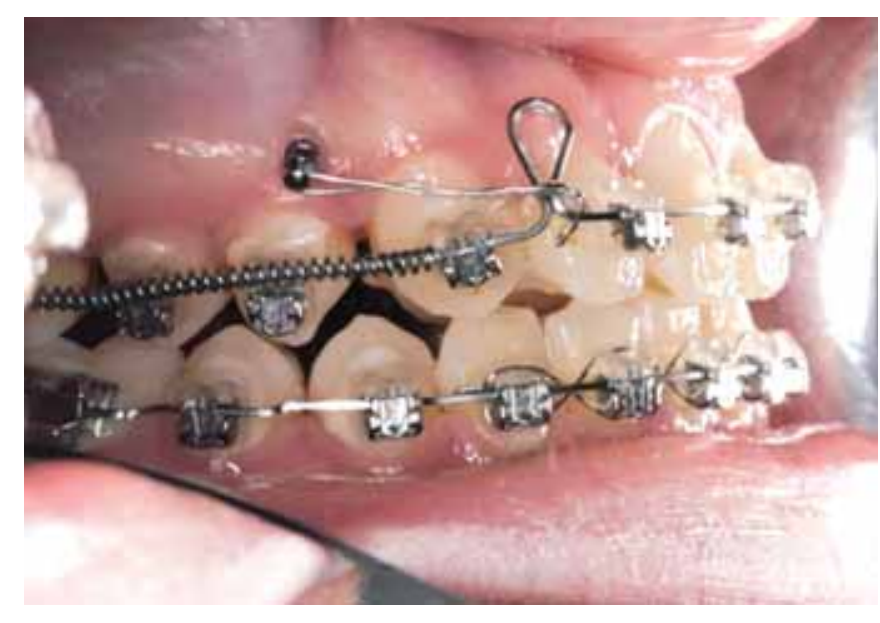

Fig. 11: Implants used for molar distalization

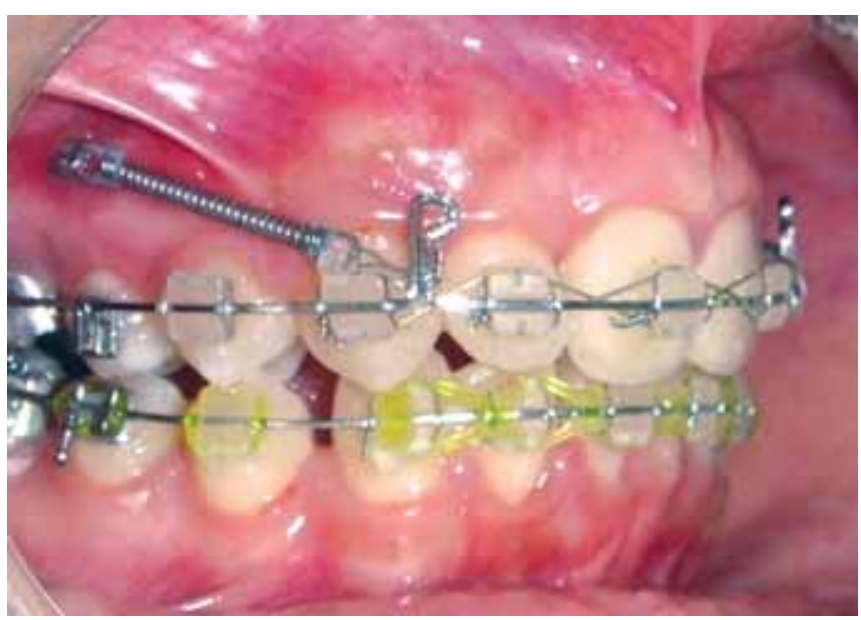

Fig. 12: Implants used for retraction of anterior teeth

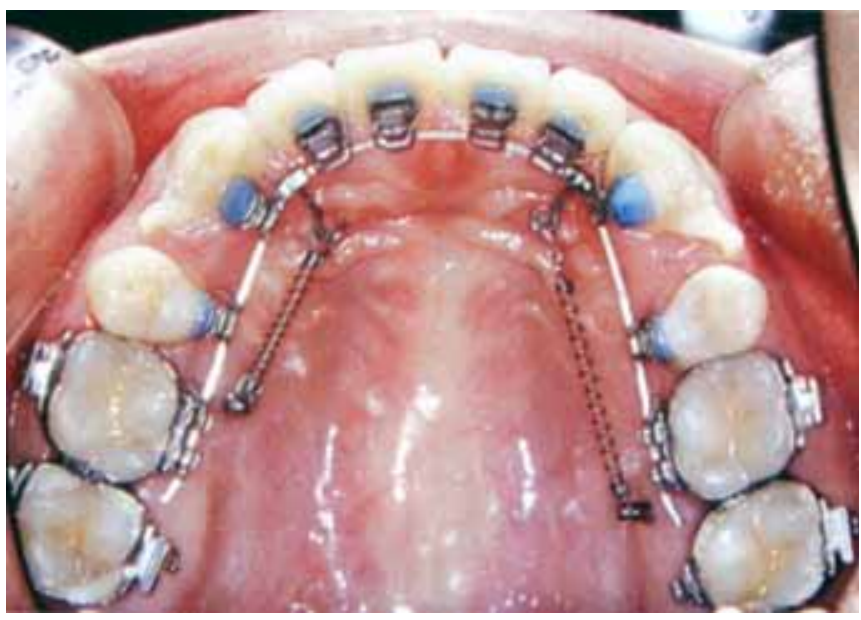

Fig. 13: Implants for retraction of anterior teeth in lingual orthodontics

\section{Skeletal Anchorage System (SAS) ${ }^{8,11}$}

The skeletal anchorage system was developed by Umemori and Sugawara (Fig. 14).

Appliance design: It essentially consists of titanium miniplates, which are stabilized in the maxilla or the 
mandible using screws. Different designs of miniplates are available and this fact offers some versatility in placing the implants in different sites (Fig. 14). The ' $L$ ' shaped miniplates have been the most commonly used ones, while the ' $\mathrm{T}$ ' shaped ones have been proposed for usage while intruding anterior teeth. The screws used for fixing the miniplate are usually 2 to $2.5 \mathrm{~mm}$ in diameter (Figs 15 to 17).

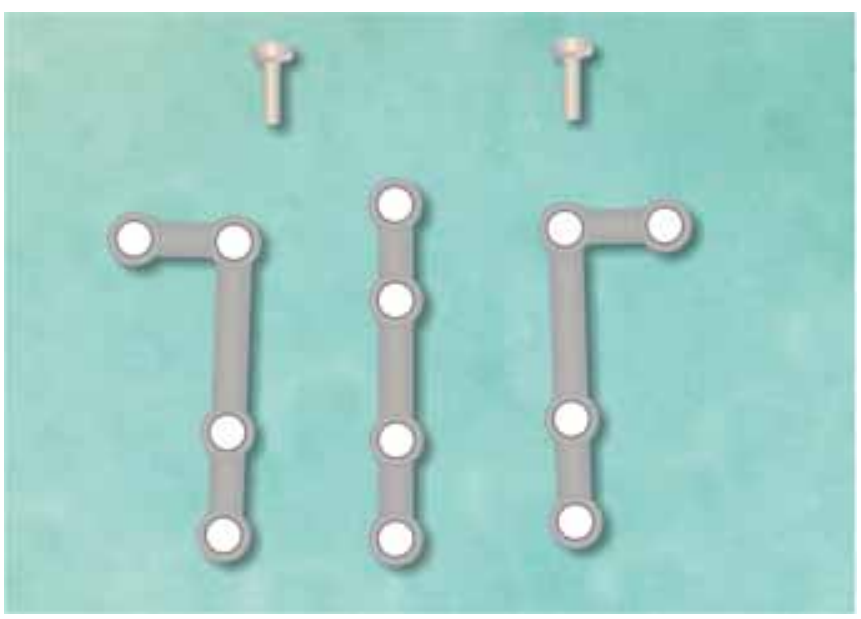

Fig. 14: Miniplates used in skeletal anchorage system

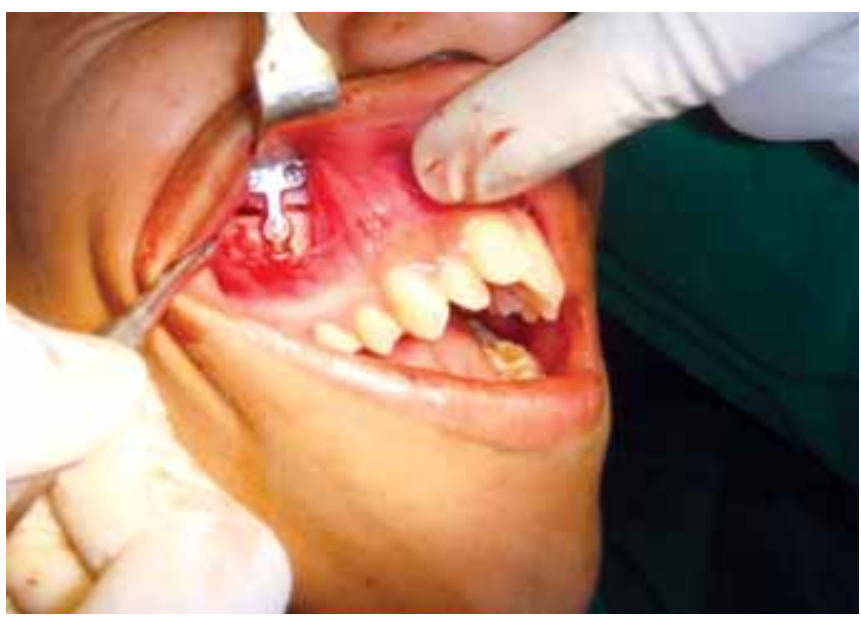

Fig. 15: Skeletal anchorage with miniplates

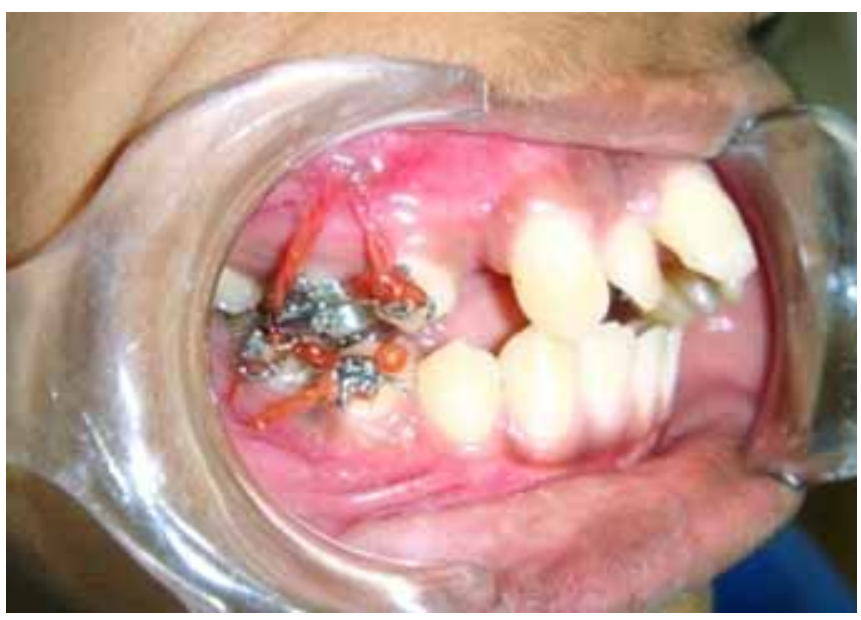

Fig. 16: Skeletal anchorage for molar intrusion application of skeletal anchorage system in upper and lower arch
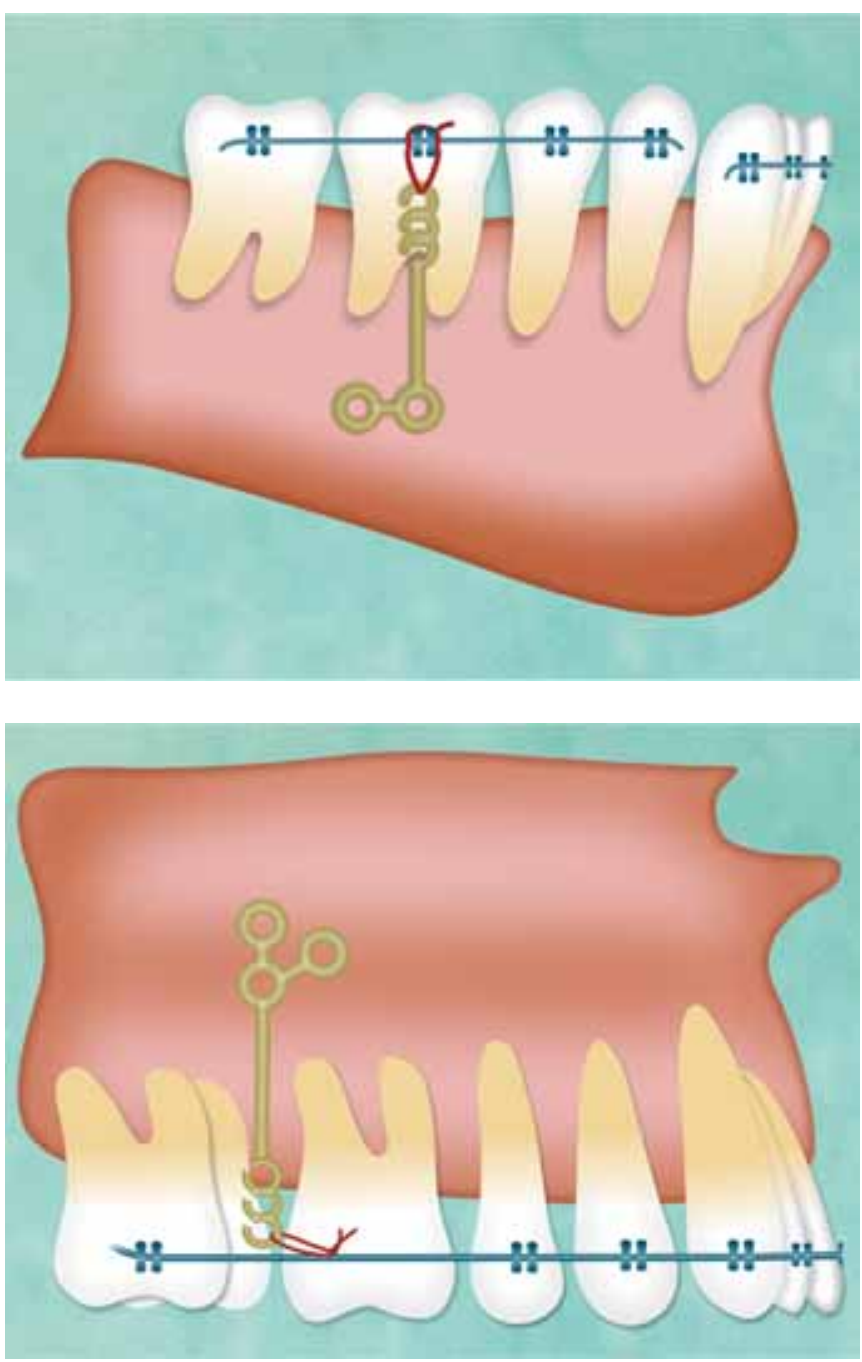

Fig. 17: Application of skeletal anchorage system in upper and lower arch

\section{CLINICAL APPLICATION}

\section{Advantage of Miniplates}

The anchor plates are monocortically placed at the piriform opening rim, the zygomatic buttresses, and any regions of the mandibular cortical bone. The anchor plates work as the onplant and the screws function as the implant, SAS enables the rigid anchorage that results from the osseointegration effects in both the anchor plates and screws. All portions of the anchor plates and screws are placed outside the maxillary and mandibular dentition, the SAS does not interfere with tooth movement.

\section{Intrusion of Molars for Correction of Open Bite ${ }^{6}$}

Intrusion of the lower molars was achieved with the application of elastic orthodontic force on the SAS, lingual crown torque was applied to the lower molars with Burstone's precision lingual arch to avoid buccal flaring during intrusion (Fig. 18). 


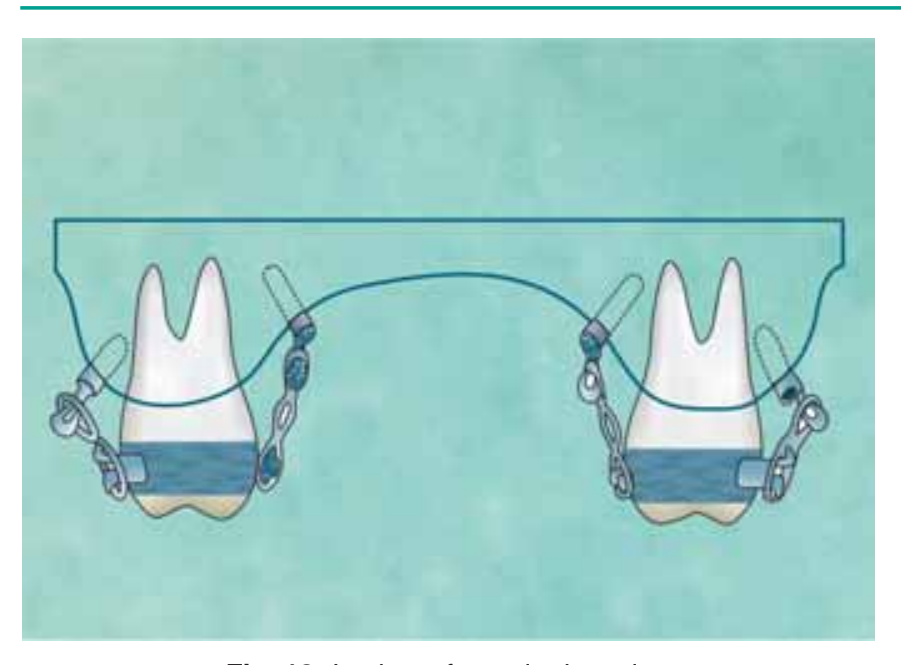

Fig. 18: Implants for molar intrusion

\section{Molar Distalization}

Extraction of the third molars is done to create the space for the molar distalization. After the buccal segments are leveled and aligned, stiff archwires, L-shaped anchor plates are placed at the anterior border of the mandibular ramus. Then the bands or brackets of the first molar are taken off, and a retractive force is applied to the second molar with an open coil spring. To avoid the side effects of the reciprocal coil spring, the first premolars must be firmly ligated with anchor plates. After the distalization of the second molar, distalization of the first molar is done with the same procedure.

\section{En Masse Distalization of the Entire Buccal Segments}

Direct retractive force is applied from the anchor plates to the first premolars to perform en masse distalization of the buccal segments. Elastic modules or nickel-titanium closed coil springs usually provide the retractive orthodontic force.

\section{RISKS AND COMPLICATIONS ${ }^{9}$}

- Implants should be placed in the inter-radicular bone between teeth. Trauma to the periodontal ligament or the dental root during insertion can lead to ankylosis, loss of vitality or osteosclerosis

- Miniscrew slippage: The clinician might fail to fully engage cortical bone during placement and inadvertently slide the miniscrew under the mucosal tissue along the periosteum

- Nerve involvement: Nerve injury can occur during placement of miniscrews in the maxillary palatal slope, the mandibular buccal dentoalveolus, and the retromolar region. Most minor nerve injuries not involving complete tears are transient with full correction in 6 months

- Air subcutaneous emphysema

- Nasal and maxillary sinus perforation

- Miniscrew bending and fracture during insertion

- Aphthous ulceration due to tissue irritation

- Soft tissue coverage of the miniscrew head and auxiliary

- Soft tissue inflammation, infection and peri-implantitis

- Miniscrew fracture during removal.

\section{LONG-TERM STABILITY OF MINI-IMPLANTS ${ }^{10}$}

Miyawaki et al analyzed the success rate of 3 different screw sizes and a miniplate design. Their sample consisted of 51 patients who had 134 different implants used for conserving anchorage. The implants were in the form of screws (134 in number) of 1.0, 1.5 and $2.3 \mathrm{~mm}$ diameter as well as 17 miniplates. On 1 year after placement, they drew the following conclusions:

a. The implant screws of $1 \mathrm{~mm}$ diameter had a high failure rate and are not recommended for clinical use as orthodontic anchors

b. Implant screws of 1.5 and $2.3 \mathrm{~mm}$ diameter had reasonable success rates — 84 and $86 \%$ respectively, and therefore could be used in majority of the cases

c. The miniplates had the best stability (96\%), but the surgical intervention and patient discomfort was greater when compared to miniscrews. Miniplates have been recommended in high angle patients

d. Peri-implant hygiene is one of the major factors which could affect the stability of these implants.

\section{REFERENCES}

1. Cheol-Ho Paik, In-Kwon Park, Youngjoo Woo, Tae-Woo Kim. Orthodontic miniscrew implants: Clinical applications. Elsevier.

2. Temporary anchorage devices in orthodontics. Elsevier. Nanda. Uribe.

3. Chung, Nelson, Kim, Kook. Severebidento alveolar protrusion treated with orthodontic microimplant-dependent en-masse retraction. AJODO 2007;132:105-15.

4. Park HS, Bae SM, Kyung HM, Sung HM. Microimplant anchorage for treatment of skeletal Class I bialveolar protrusion. J Clin Orthod 2001;35:417-22.

5. Ohnishi H, Yahi T, Yasuda Y, Takada K. A mini-implant for orthodontic anchorage in a deep overbite case. Angle Orthod 2005;75:444-52. 
6. Sherwood, Burch, Thompson. Closing anterior open bites by intruding molars with titanium miniplate anchorage. AJODO 2002;122:593-600.

7. Kanomi R. Mini-implant for orthodontic anchorage. J Clin Orthod 1997;31:763-67.

8. Umemori, Sugawara, Mitani, Nagasaka, Kawamura.Skeletal anchorage system for open-bite correction. AJODO 1999;115:166-74.
9. Kravitza, Kusnotob. Risks and complications of orthodontic miniscrews. AJODO 2007;131:145.

10. Miyawaki et al.Factors associated with the stability of titanium screws placed in the posterior region for orthodontic anchorage. AJODO 2003;124:373-78

11. H De Clerck Bollard Skeletal Anchorage in Orthodontics. www.boneanchor.be. 